\title{
CARBON DIOXIDE SEPARATION BY PHASE ENHANCED GAS-LIQUID ABSORPTION
}

\author{
ANNUAL PROJECT PROGRESS REPORT
}

REPORTING PERIOD START DATE: SEP. 2002

REPORTING PERIOD END DATE: AUG. 2004

PRINCIPAL AUTHORS: DR. LIANG HU \& DR. ADEYINKA A. ADEYIGA

MAY 2004

DOE AWARD NUMBER: DE-FG26-02NT41668

SCHOOL OF ENGINEERING AND TECHNOLOGY

HAMPTON UNIVERSITY

HAMPTON, VA 23668 


\section{DISCLAIMER}

This report was prepared as an account of work sponsored by an agency of the United States Government. Neither the United States Government nor any agency thereof, nor any of their employees, makes any warranty, express or implied, or assumes any legal liability or responsibility for the accuracy, completeness, or usefulness of any information, apparatus, product, or process disclosed, or represents that its use would not infringe privately owned rights. Reference herein to any specific commercial product, process, or service by trade name, trademark, manufacturer, or otherwise does not necessarily constitute or imply its endorsement, recommendation, or favoring by the United States Government or any agency thereof. The views and opinions of authors expressed herein do not necessarily state or reflect those of the University States Government or any agency thereof. 


\begin{abstract}
A new process called phase enhanced gas-liquid absorption has been developed in its early stage. It was found that adding another phase into the absorption system of gas/aqueous phase could enhance the absorption rate.

A system with three phases was studied. In the system, gas phase was carbon dioxide. Two liquid phases were used. One was organic phase. Another was aqueous phase. By addition of organic phase into the absorption system of $\mathrm{CO}_{2}$-aqueous phase, the absorption rate of $\mathrm{CO}_{2}$ was increased significantly. $\mathrm{CO}_{2}$ finally accumulated into aqueous phase. The experimental results proved that

(1) Absorption rate of carbon dioxide was enhanced by adding organic phase into gasaqueous phase system;

(2) Organic phase played the role of transportation of gas solute $\left(\mathrm{CO}_{2}\right)$. Carbon dioxide finally accumulated into aqueous phase.
\end{abstract}




\section{TABLE OF CONTENTS}

$\begin{array}{ll}\text { INTRODUCTION } & 5\end{array}$

EXECUTIVE SUMMARY 5

$\begin{array}{lr}\text { EXPERIMENT } & 6\end{array}$

RESULTS AND DISCUSSION

$\begin{array}{ll}\text { CONCLUSION } & 13\end{array}$ 


\section{INTRODUCTION}

Up to now, absorption is still a powerful tool for the gas separation and

purification [Arthur L. Kohl \& Fred C. Riesenfeld; Gas Purification. $4^{\text {th }}$ Edition; Gulf Publishing Company; 1985]. However, current processes for the enhancement of gas liquid absorption rate are still limited to the chemical reactions, which occur, in the liquid phase between gas component and liquid solution. The drawback is obvious. The reaction will cause difficulty for the release of the gas components from liquid. The chemical reaction brings two benefits for absorption. One is the increase of carrying capacity for gas components. Another is the reduce of mass transfer resistance or increase of mass transfer coefficient. Both factors contribute to the increase of absorption rate.

Sartori and Savage [Arthur L. Kohl \& Fred C. Riesenfeld; Gas Purification. $4^{\text {th }}$ Edition; Gulf Publishing Company; 1985, p 235] compared absorption rates and vaporliquid equilibria of $\mathrm{CO}_{2}$ in unpromoted hot potassium carbonate solutions with solutions promoted with diethanolamine (DEA) and solutions promoted with sterically hindered amines. Both DEA and sterically hindered amines were found to be very effective in increasing the rate of $\mathrm{CO}_{2}$ absorption. However equilibrium partial pressure of $\mathrm{CO}_{2}$ is decreased after activator added into the carbonated solution. This means that it is more difficulty to release $\mathrm{CO}_{2}$ from activated solution than unactivated solution.

Phase enhanced absorption provides a new method for gas liquid absorption. By introducing another liquid phase into original absorption system to improving mass transfer resistance, the absorption rate is able to be increased significantly. More important, the increase of absorption rate does not cause any difficulty of regeneration.

\section{EXECUTIVE SUMMARY}

Absorption is a process by which one or more components of a gas mixture are transferred to a liquid where it is soluble. The operation of absorption can be categorized on the basis of the nature of the interaction between absorbent and absorbate into following two types, traditionally:

Physical absorption: The component being absorbed in physical absorption is more soluble in the liquid absorbent than other gas components with which it is mixed, but does not react chemically with the absorbent. 
Chemical absorption: Chemical absorption is characterized by the occurrence of a chemical reaction between the gas component being absorbed and a component in the liquid to form a compound.

Phase enhanced absorption or Phase enhanced gas-liquid absorption: In the study, it was found that by adding an organic compound or mixture into a gas-liquid (frequently, an aqueous phase) absorption system, the absorption rate of the gas can increase significantly. Therefore, the process occurring in this system is referred to as phase enhanced gas-liquid absorption. In phase enhanced gas-liquid absorption, more than one liquid phase was involved in absorbing the gas. One of the liquids serves as an absorbing carrier where the gas is finally accumulated. The other liquid, the transportation layer, plays a role of transporting the gas from the gas mixture to the carrier and increasing the absorption rate of the gas.

A new process called phase enhanced gas-liquid absorption has been developed in its early stage. It was found that adding another phase into the absorption system of gas/aqueous phase could enhance the absorption rate.

A system with three phases was studied. In the system, gas phase was carbon dioxide. Two liquid phases were used. One was organic phase. Another was aqueous phase. By addition of organic phase into the absorption system of $\mathrm{CO}_{2}$-aqueous phase, the absorption rate of $\mathrm{CO}_{2}$ was increased significantly. $\mathrm{CO}_{2}$ finally accumulated into aqueous phase. The experimental results proved that

(1) Absorption rate of carbon dioxide was enhanced by adding organic phase into gasaqueous phase system;

(2) Organic phase played the role of transportation of gas solute $\left(\mathrm{CO}_{2}\right)$. Carbon dioxide finally accumulated into aqueous phase.

\section{EXPERIMENT}

The major analytical method for this project is the measurement of gas absorption rate. The experimental procedure and principle are described as follows:

The absorption rate of gas, carbon dioxide, was measured by two foam film flow meters. One is installed before the inlet of the stirring cell; another is installed after the 
outlet of the stirring cell. To determine the absorption rate, gas flow rate is measured by both foam film flow meters at the same time period. The difference of two flow rates, in and out of the stirring cell is the absorption rate.

The experimental equipment is shown as in Figure 1:

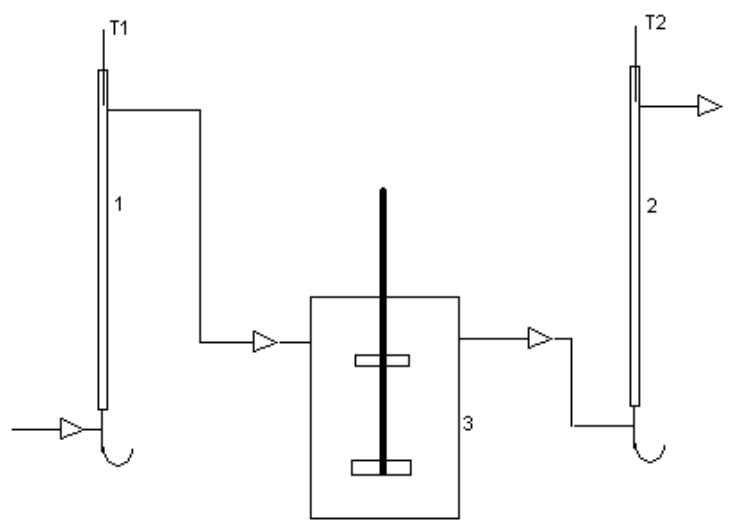

T1, T2 --- Thermometer; 1, 2 --- Foam film flow meter; 3 --- Absorption cell Figure 1. Experimental equipment for the measurement of absorption rate

Experimental step:

(1) Measure the flow rate of gas in and out of the absorption cell at the same time (volume flow rate);

(2) Measure the temperature of each foam film flow meter;

(3) Use idea gas equation to calculate the mass flow rate;

(4) Subtract the flow rate of gas in and out of the absorption cell, which is equal to the absorption rate.

Calculation:

The idea gas equation: $\quad \mathrm{PV}=\mathrm{nRT}$

Divide by time t: $\quad \mathrm{PV} / \mathrm{t}=\mathrm{RTn} / \mathrm{t}$

The mass flow rate: $\mathrm{n} / \mathrm{t}=\mathrm{PV} /(\mathrm{tRT})$

Subtract mass flow rate of in and out of absorption cell, which is the absorption rate:

$$
(\mathrm{n} / \mathrm{t})_{1^{-}}(\mathrm{n} / \mathrm{t})_{2}=\mathrm{PV}_{1} /\left(\mathrm{tRT}_{1}\right)-\mathrm{PV}_{2} /\left(\mathrm{tRT}_{2}\right)
$$

The experimental apparatus has been set up as shown in Figure 2. 


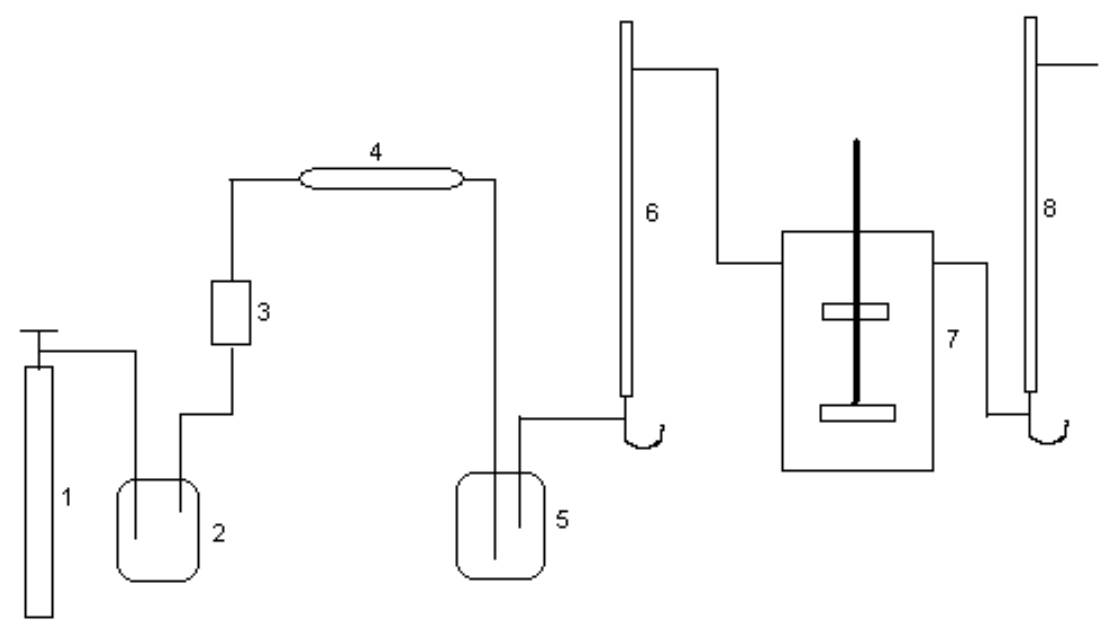

1. gas cylinder

2. pressure buffer

3. rotating flow meter

4. gas filter

5.

saturator

6, 8. foam film flow meter

7. absorption cell

\section{Figure 2. Experimental apparatus}

$\mathrm{CO}_{2}$ gas from cylinder entered into gas pressure buffer 2 to stabilize pressure. Gas flow rate was controlled by rotating flow meter 3 . After filtered by gas filter $4, \mathrm{CO}_{2}$ gas flowed through saturator 5 where gas was saturated by absorbent. $\mathrm{CO}_{2}$ gas was measured by foam film flow meter 6 before entering into absorption cell 7. After absorption, $\mathrm{CO}_{2}$ was measured again by foam film flow meter 8 .

\section{RESULTS AND DISCUSSION}

The following experiments were designed to study the phase enhanced absorption:

\section{Absorption Rate of Carbon Dioxide in the Organic Mixture and in the Liquid}

\section{Carrier}

The experiments were conducted to determine the effects of the transportation layer. Carbon dioxide absorption rates in a liquid carrier and in an organic mixture were measured individually under the same experimental conditions: $\mathrm{T}=25{ }^{\circ} \mathrm{C}, \mathrm{p}=1.0 \mathrm{~atm}$, carbon dioxide concentration=99.9\% by volume, agitation speeds $=250$ and $106 \mathrm{rpm}$ (for two different runs). The liquid carrier was made of $300 \mathrm{ml}$ of $400 \mathrm{~g} / \mathrm{L}$ sodium formate 
aqueous solution and the organic mixture was $300 \mathrm{ml}$ Alamine 336 and 2-ethylhexyl alcohol (1:1 ratio by volume).

The results from those experiments are shown in FIG. 5A and 5B. Carbon dioxide was absorbed by the organic mixture much faster than it was by the liquid carrier. FIG. 5A shows different absorption rates for the two experiments performed with agitation speed being 250 rpm. FIG. 5B shows the result from the two experiments conducted at the agitation speed of $106 \mathrm{rpm}$. It can be seen that the absorption rate of carbon dioxide in the liquid organic mixture was about ten times more than that in the liquid carrier.

By comparing the absorption rates in FIGS. 5A and 5B, it is apparent that when the liquid carrier and the organic mixture existed in the same gas-liquid absorption system, the slow absorption of carbon dioxide by the liquid carrier did not limit the rate at which carbon dioxide was absorbed under the experiment condition.

The relationship between the absorption rate of carbon dioxide and absorption time is shown in FIGS. 6A and 6B. It is obvious that carbon dioxide reached equilibrium in the liquid organic mixture much earlier than that in the liquid carrier. So, the organic mixture was saturated by carbon dioxide much earlier than by the liquid carrier when both existed in the same system.

The experimental results also shows that the mass transfer resistance of carbon dioxide in the organic mixture was much lower than that in liquid carrier.

\section{$\mathrm{CO}_{2}$-sodium Formate Aqueous Solution Absorption System}

In this example, two experiments were conducted. In the first experiment, carbon dioxide was absorbed by $280 \mathrm{ml}$ sodium formate aqueous solution (400 g/1) and $20 \mathrm{ml}$ organic mixture of Alamine 336 and 2-ethy1hexyl alcohol (1:1 by volume). In the second experiment, carbon dioxide was absorbed by $300 \mathrm{ml}$ sodium formate aqueous solution (400 g/1) directly.

In the first experiment, $280 \mathrm{ml}$ sodium formate aqueous solution (400 g/L) and 20 ml liquid organic mixture were added into the reaction vessel. The liquid organic mixture, which was immiscible with the aqueous solution, formed a layer, as a second liquid phase, on top of the liquid carrier. The liquid carrier was agitated gently to facilitate the diffusion or dissolving of the gas. Agitating was sufficiently gentle so the convection moment it created did not break or destroy the layer of the liquid organic 
mixture. Carbon dioxide from the gas had to pass through the layer of the organic mixture in order to enter the aqueous solution. In the second experiment, $300 \mathrm{ml}$ sodium formate aqueous solution ( $400 \mathrm{~g} / \mathrm{L})$ was introduced into the reaction vessel. No liquid organic mixture was added. Both experiments were conducted under the same experimental conditions: temperature $=25{ }^{\circ} \mathrm{C}$, pressure $=1.0 \mathrm{~atm}$, agitation speed $=250 \mathrm{rpm}$, and the concentration of carbon dioxide $=99.9 \%$ by volume.

FIG. 4 shows that the absorption rate of carbon dioxide in the first experiment was higher than that in the second experiment. Clearly, the sodium formate aqueous solution absorbed carbon dioxide faster in the presence of the liquid organic mixture than it did in the absence of it.

FIGURE 4

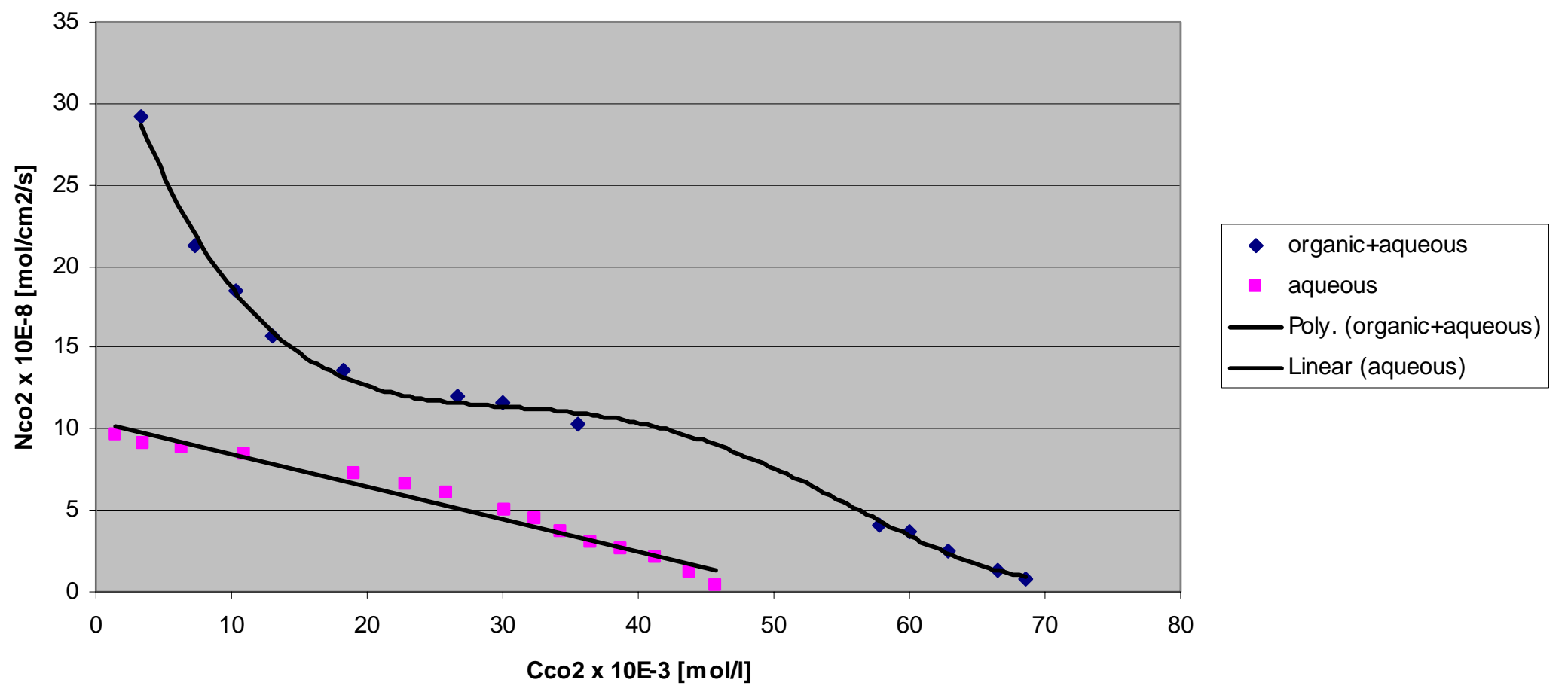


FIGURE 5 A

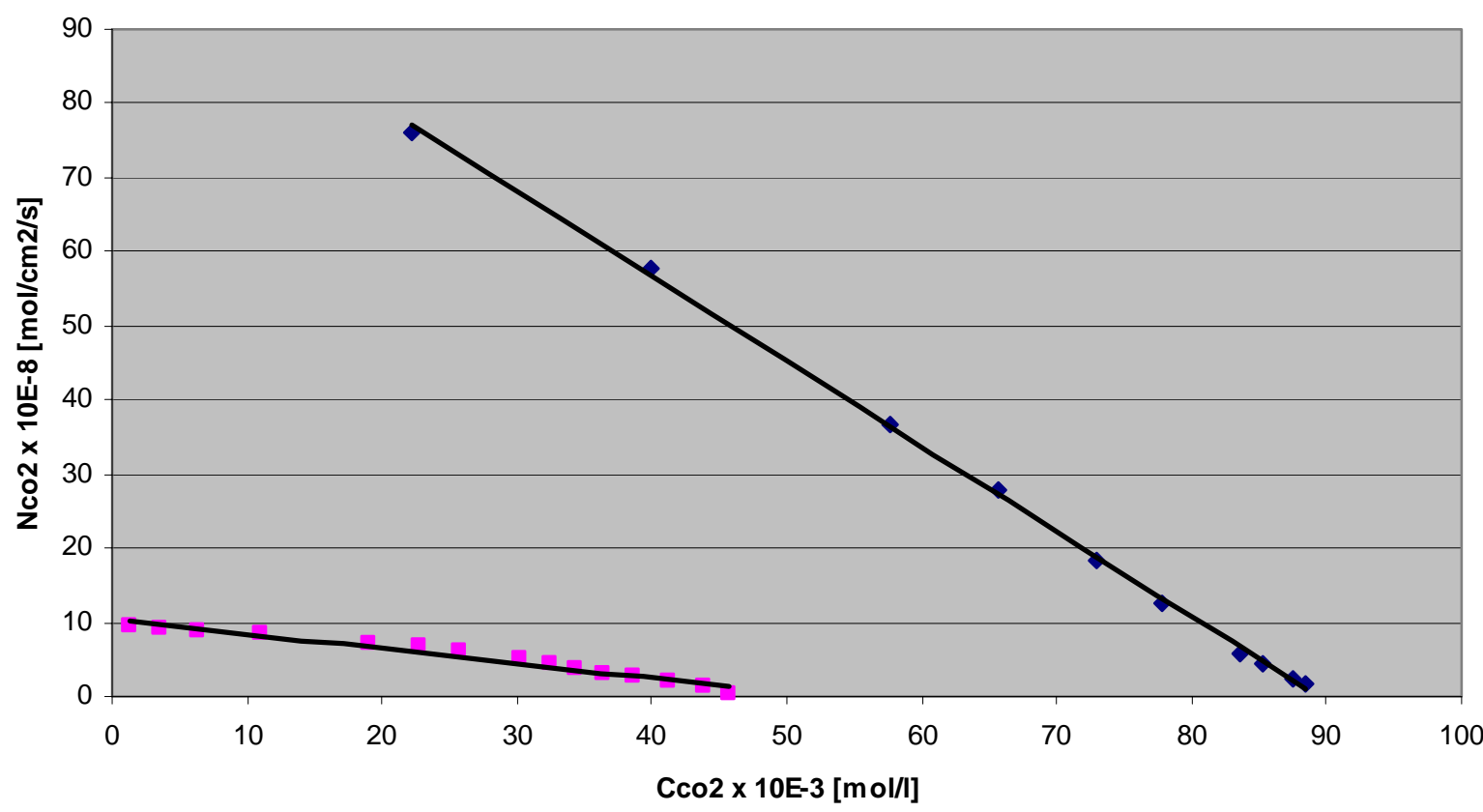

- organic

- aqueous

— Linear (organic)

— Linear (aqueous)

FIGURE 5 B

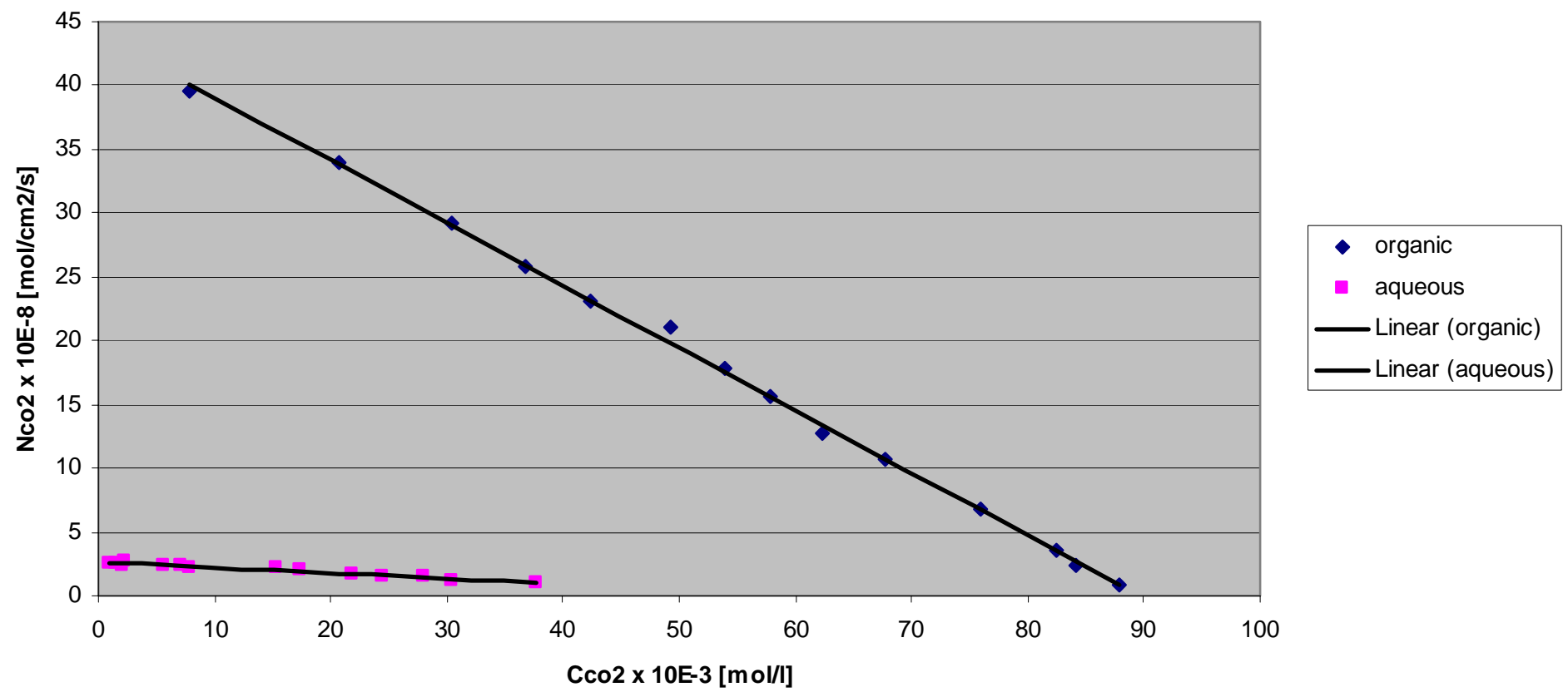


FIGURE 6 A

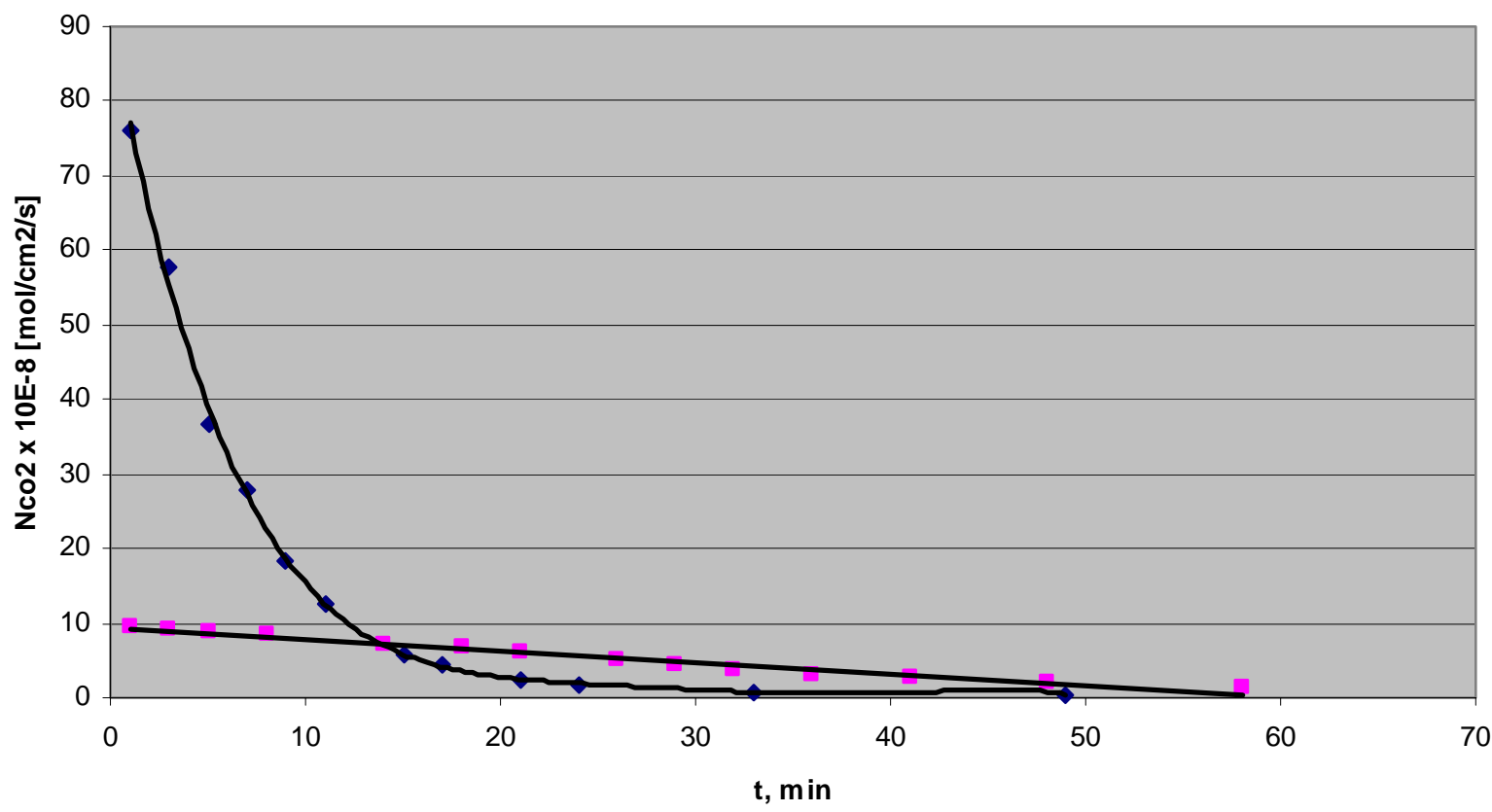

- organic

- aqueous

_Poly. (organic)

_Linear (aqueous)

FIGURE 6 B

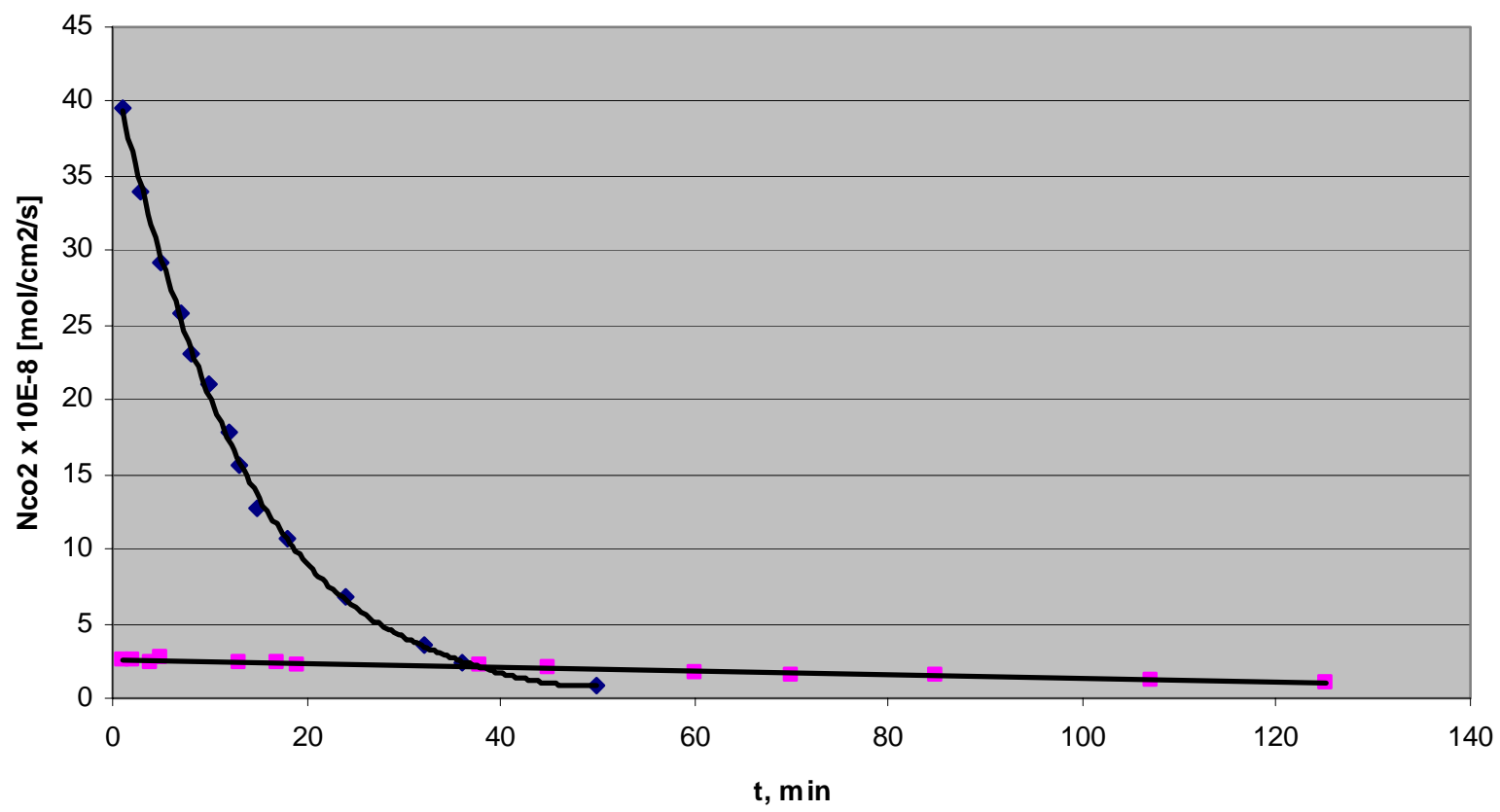

- organic

- aqueous

_—Poly. (organic)

_Linear (aqueous) 


\section{CONCLUSION}

A new process called phase enhanced gas-liquid absorption has been developed in its early stage. It was found that adding another phase into the absorption system of gas/aqueous phase could enhance the absorption rate. 